\title{
Strategic Jet Engine System Design in Light of Uncertain Fuel and Carbon Prices
}

\author{
Stephan Langmaak ${ }^{1}$ and James Scanlan ${ }^{2}$ \\ University of Southampton, Southampton, SO17 1BJ, United Kingdom \\ and \\ Stephen Wiseall ${ }^{3}$ \\ Rolls-Royce plc, Derby, DE24 8BJ, United Kingdom
}

\begin{abstract}
Since the Wright brothers took to the skies over 100 years ago, aviation has been powered by fossil fuels. This dependency will not be markedly reduced within the next two decades despite higher and more erratic fuel prices that result from increasingly restricted access to crude oil. Climate change will also force regulators to increase the price of $\mathrm{CO}_{2}$ emissions so that there is an even greater incentive to operate fuel efficient aircraft. This project therefore aims to investigate how the profit generated by a short-range jet engine can be made robust to uncertain fuel and carbon prices in 2030 by applying the Surplus Value Methodology in conjunction with Robust Design techniques.
\end{abstract}

\section{Introduction}

\section{A. Energy}

1. Impact of Fuel Prices

RETWEEN 1971 and 2009, the 12-month average oil price fluctuated between $\$ 15$ and over $\$ 90$ per barrel in 2010 prices, which in turn caused the fuel cost fraction to vary between $10 \%$ and over $30 \%$ of the Total Operating Cost of U.S. airlines ${ }^{*}$ as Fig. 1 on the next page proves.

\section{Peak Oil \& Oil Price Predictions}

Although less than half of the planet's crude oil reserves have been used up, the remaining oil will be more difficult and expensive to extract, which will slow production, increase oil prices and have controversial environmental and social impacts ${ }^{t, \neq}$. Various independent sources forecast that maximum oil extraction will occur between 2009 and 2031 and there is a significant risk that it will happen before $2020^{\xi, * *++, 1,2}$. Although the decline will not be sudden, the equivalent of a new Saudi

\footnotetext{
${ }^{1}$ EngD Research Engineer, Computational Engineering and Design, School of Engineering Sciences.

2 Professor of Design, Computational Engineering and Design, School of Engineering Sciences, AIAA Member.

${ }^{3}$ Team Leader, Cost Methods, Engineering \& Technology.

* Air Transport Association (ATA) Quarterly Cost Index for U.S. passenger airlines. Available from: http://www.airlines.org/Economics/DataAnalysis/Pages/QuarterlyCostIndex.aspx

${ }^{\dagger}$ Guardian.co.uk, "Peak Oil Could Hit Soon, Report Says," The Guardian, 2009. Available from: http://www.guardian.co.uk/environment/2009/oct/08/peak-oil-could-hit-soon

${ }^{\ddagger}$ Saven, J., "Peak Oil Predictions," The Guardian, 2010. Available from:

http://www.guardian.co.uk/commentisfree/2010/apr/23/peak-oil-energy-recession

$\S$ Porter, A., "'Peak Oil' Enters Mainstream Debate," BBC News, 2005. Available from: http://news.bbc.co.uk/1/hi/4077802.stm

${ }^{* *}$ Schultz, S., "Military Study Warns of a Potentially Drastic Oil Crisis," Spiegel Online International, 2010. Available from: http://www.spiegel.de/international/germany/0,1518,715138,00.html

${ }^{+\dagger}$ Connor, S., "Warning: Oil Supplies are Running Out Fast," The Independent, 2009. Available from: http://www.independent.co.uk/news/science/warning-oil-supplies-are-running-out-fast-1766585.html 
Arabia has to be tapped every three years and more than two thirds of the current oil production capacity has to be replaced by $2030^{2}$. Sir Richard Branson ${ }^{\ddagger \neq}$, the founder of the Virgin Group, expects that "the next five years will see us face another crunch: the oil crunch."

In July 2008 , jet fuel prices peaked at $\$ 4.33$ per U.S. gallon, but plummeted to $\$ 1.28$ by late December ${ }^{3}$. Although historically that is an extreme example, the previous paragraph explained why high and erratic prices ${ }^{\dagger}$ will become more common in the future. After the current recession, fuel cost is therefore likely to represent the biggest part of the Total Operating Cost again, just like between 2006 and 2008. Although "air ticket prices have reached their lowest level and will never be as low again ${ }^{1}, "$ air cargo is even more affected by fuel prices because there are no additional passengerrelated costs ${ }^{3}$.

Due to the lack of data transparency, oil price projection is a matter of debate rather than science $^{\S}$. It is therefore not surprising that various institutions predict significantly different oil prices, even in the short term. Consequently, the forecasts various sources make for 2030 vary between $\$ 55$ and $\$ 305$ per barrel in 2008 prices $^{4-7}$.

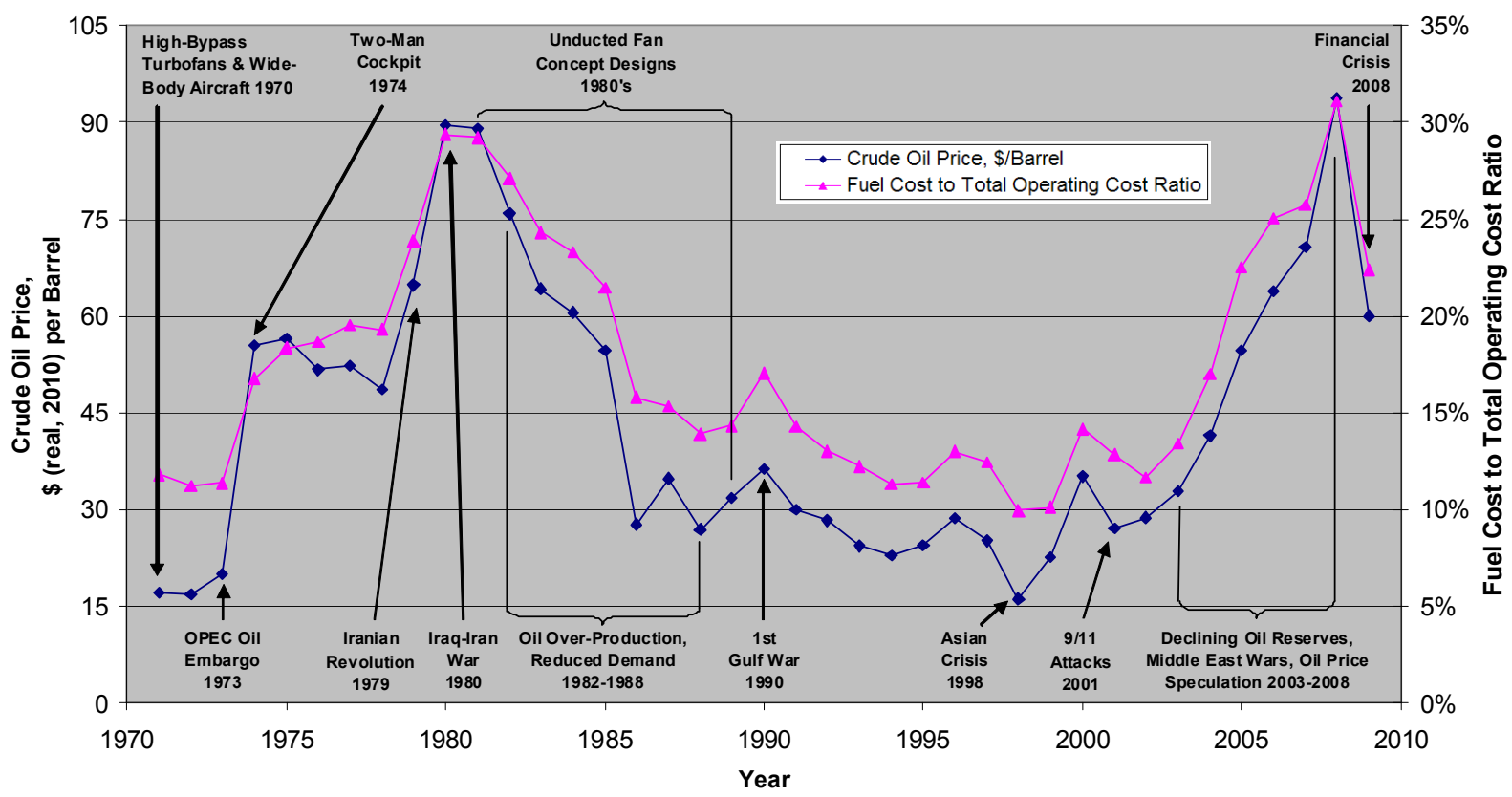

Figure 1. Historical Correlation Between Oil Price \& Fuel Operating Cost (based on ATA* data for U.S. airlines)

\section{B. Environmental Regulation}

\section{Impact of Aircraft Emissions}

To ensure that pre-industrial temperatures are not exceeded by more than 2.0 to $2.4{ }^{\circ} \mathrm{C}$ on average, global $\mathrm{CO}_{2}$ equivalent emissions have to drop by $50-85 \%$ by 2050 relative to the year $2000^{1}$. In order to meet this target, "all industry sectors, including aviation, need to contribute their share of emissions reduction ${ }^{1}$." Thus, the British government has introduced legislation that economy wide emissions have to be reduced by $80 \%$ by 2050 with respect to $1990^{5}$ and has stated that "the total emissions from aviation in 2050 must be no higher than in $2005^{8}$."

In 1992 , aviation accounted for $3.5 \%^{9,10}$ of the global anthropogenic radiative forcing and $2 \%{ }^{1,10}$ of global $\mathrm{CO}_{2}$ emissions. While air traffic is expected to grow approximately $5 \%^{1,3,10}$ per year, specific fuel consumption is projected to decrease by only $0.7-1.5 \%{ }^{1,5}$ per annum. As this results in a net increase in aircraft emissions, aviation's share in global man-made radiative forcing is predicted to

${ }^{\ddagger \ddagger}$ Guardian.co.uk, "Energy Minister Will Hold Summit to Calm Rising Fears over Peak Oil," The Guardian, 2010. Available from: http://www.guardian.co.uk/business/2010/mar/21/peak-oil-summit 
increase to $5 \%^{1,9,10}$ by 2050 . Considering that the aviation industry has agreed to pay its full external costs $^{9}$, the only way to legitimise and secure the aviation business in the long-run is through a 'clean approach $^{11}$ where growth and ecological damage are uncoupled.

\section{Carbon Trading}

Economic instruments are more cost efficient and flexible in comparison to fixed regulation ${ }^{11}$. The British government, the aviation industry as well as environmental groups therefore believe that for an international industry, international emissions trading across all industrial sectors is the best solution $^{9,12}$.

In 2005, the European Union set up the EU Emission Trading Scheme, which is a 'cap and trade' system for anthropogenic $\mathrm{CO}_{2}$ production ${ }^{11,13}$. For each installation registered in the scheme an emission cap is defined and every company that exceeds its quota has to buy unused credits from corporations that are better at reducing their $\mathrm{CO}_{2}$ production ${ }^{9}$. The aviation sector will be included in the scheme as from $2012^{8,13}$. This means that all operators within the EU that fly aircraft with a maximum take-off weight above $5700 \mathrm{~kg}$ will be obliged to participate, including non-EU airlines that offer flights from or to EU airports ${ }^{11,13}$.

Based on ATA $^{*}$ data, today a passenger has to fly approximately 5400 miles on an 11 hour-flight from Seattle to Beijing, for example, in order to emit 1 tonne of $\mathrm{CO}_{2}$. Considering that $\mathrm{CO}_{2}$ was traded at around $£ 12$ per tonne in late 2009 shows that currently the EU Emission Trading Scheme would have a relatively small impact on ticket prices in comparison to the predicted increases in fuel costs ${ }^{8}$. In order to achieve significant emission reductions and encourage airlines to operate the latest generation of aircraft, 1 tonne of $\mathrm{CO}_{2}$ would have to cost between $€ 100$ and $€ 300^{8}$. The independent UK Committee on Climate Change ${ }^{5}$ predicts that 1 tonne of $\mathrm{CO}_{2}$ will cost between $£ 35$ and $£ 105$ in 2030.

\section{Advanced Jet Engine Technologies}

It takes around 10 years to develop a jet engine, which then usually remains in production for more than two decades ${ }^{1,14}$. Similar to the rest of the aerospace industry, gas turbine makers therefore have to make multi-billion investments into these large and long-term projects and it normally takes at least 15 years until the costs are recuperated ${ }^{1}$. Consequently, the strategic design team must make a sound prediction 30 years into the future to ensure that their product remains competitive.

In the 1990s, engine efficiency improvement dropped to $0.5 \%$ per year as existing technologies were approaching their natural limits ${ }^{9}$. In order to deliver significant improvements, novel design solutions will have to be sought that will require investments in the order of tens of billions of Pound Sterlings $\mathrm{s}^{5,15}$. These include the widespread application of integrated bladed discs, commonly known as blisks, the more-electric aircraft, the geared turbofan, and more radical solutions like the unducted fan, also known as the open rotor or propfan.

\section{Blisks}

Blisks are currently found in the compressor of jet engines and are up to $30 \%$ lighter $^{14}$ than conventional blade and disc assemblies as Fig. 2 indicates. The lower weight permits a much higher blade speed and hence higher pressure ratios per stage ${ }^{16}$. A blisk compressor therefore requires one third fewer rotor stages to achieve the same total pressure ratio as a conventional design ${ }^{16}$.

\section{More-Electric Engine}

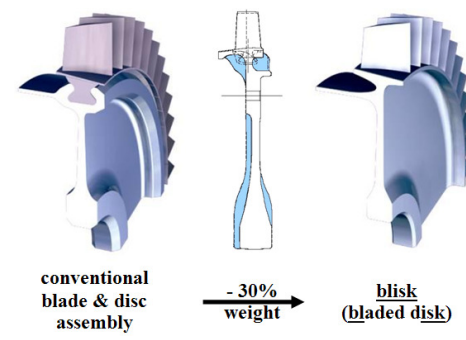

Figure 2. Blisk

While Aviation International News ${ }^{\S \S}$ writes that the more-electric aircraft requires $2 \%$ less fuel than traditional designs, other sources ${ }^{17, * * *}$ argue that there is no overall benefit currently because of

$\S \S$ Dubois, T., "Airbus Validating Electric Technologies," Aviation International News Online, 2006.

Available from: http://www.ainonline.com/airshow-convention-news/farnborough-air-show/singlepublication-story/browse/0/article/airbus-validating-electric-technologies3858/?no cache $=1 \&$ tx ttnews $\% 5$ Bstory pointer\%5D $=6 \&$ tx ttnews $\% 5 B$ mode $\% 5 \mathrm{D}=1$

Ogando, J., "Boeing's 'More Electric' 787 Dreamliner Spurs Engine Evolution," Design News, 2007. Available from: http://www.designnews.com/article/10156-

Boeing $s$ More Electric 787 Dreamliner Spurs Engine Evolution.php 
the weight penalty. Aerospace America ${ }^{17}$ does admit, however, that the more-electric aircraft offers more potential for improvement than conventional systems.

\section{Geared Fan}

Another way of reducing fuel consumption is by using a larger fan so that the bypass ratio and hence the propulsive efficiency of the engine are increased. While the fan is more efficient when it turns slowly, the low-pressure turbine blades, that drive the fan, can extract more energy from the hot gas when they turn quickly. One way of decoupling this inter-dependency is by installing a planetary gear system, like the one shown in Fig. 3, so that the fan can run at a third of the speed of the low-pressure turbine for example ${ }^{t+t}$.

\section{Unducted Fan}

As the weight of the nacelle limits the bypass ratio of the geared turbofan, the only way to further increase efficiency is by using an unducted fan, illustrated in Fig. 4, or a turboprop engine with even higher bypass ratios. Despite higher thrust levels and cruise speeds in comparison to the turboprop, in the near-term the open rotor will only be used on short-haul aircraft because it cannot match the cruise velocity of the turbofan ${ }^{1,5, \neq \neq \neq}$. Although the open rotor's large fan is also noisier ${ }^{1, \neq \neq \neq}$ and causes greater installation problems ${ }^{5,15,++\dagger}$ than the geared fan, the former is $20-25 \%{ }^{1}$ more efficient than today's short-range jet engines, whereas the geared fan only enables a fuel

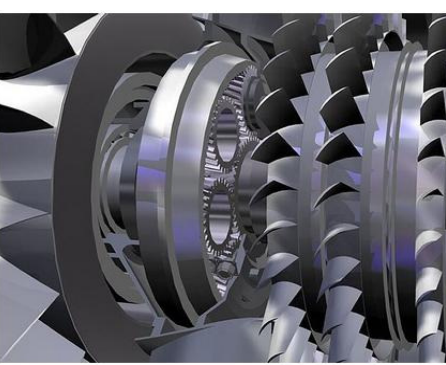

Figure 3. Geared Fan ${ }^{+\dagger}$

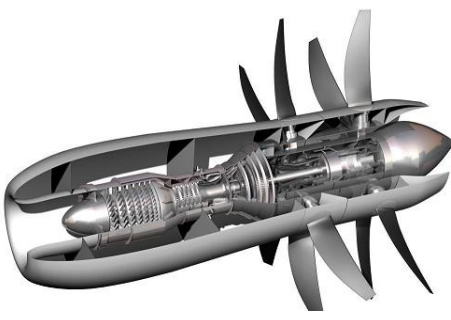

Figure 4. Open Rotor ${ }^{\ddagger \neq \neq}$ efficiency improvement of $10-15 \%$ $\$ \S \S$.

\section{Strategic Jet Engine Design Methodology}

\section{A. Uncertainty}

The Advisory Council for Aeronautics Research in Europe (ACARE) ${ }^{1}$ states: "The future is uncertain, except that changes will be rapid and marked, especially in the price of resources, and this scenario will become a normal phenomenon." The author therefore believes that the best forecasting tool is one that quantifies the underlying uncertainty of future oil and carbon prices.

Based on the maximum and minimum oil and carbon price estimates for 2030 mentioned previously and a fuel efficiency improvement of $1.0 \%$ per annum, the pessimistic Total Operating Cost prediction in Fig. 5 on the next page is twice as high as the optimistic one. This infers that it is extremely difficult for jet engine manufacturers to design a product that is guaranteed to still be successful several decades later.

\section{B. Robust Design}

When optimising a design, its performance should not simply be maximised by taking the product to its limits where a slight perturbation could lead to a significant loss in performance ${ }^{18}$. Instead, the design should be made more robust by placing it on a performance plateau within the design space where the performance is hardly affected by variability ${ }^{18}$.

${ }^{+++}$Warwick, G., "Civil Engines: Pratt \& Whitney Gears up for the Future with GTF," Flightglobal, 2007. Available from: http://www.flightglobal.com/articles/2007/11/30/219989/civil-engines-pratt-whitneygears-up-for-the-future-with.html

f¥¥ Warwick, G., "Noise Tests Keep Promise of Open-Rotor Engines Alive," Aviation Week, 2010. Available from:

http://www.aviationweek.com/aw/displaystory.do?parameter=displayStory\&story=xml/awst xml/201 0/01/25/AW_01 25 2010_p80-194921.xml\&headline=Noise+Tests+Keep+Promise+Of+OpenRotor+Engines+Alive\&pubKey=awst\&channel=outlook Engines §§§ Govindasamy, S., "Airbus A320neo to Enter Service in 2016," Flightglobal, 2010. Available from: http://www.flightglobal.com/articles/2010/12/01/350357/airbus-a320neo-to-enter-service-in2016.html 
Thus, this project will investigate how to increase the chances of maximising the profit a shortrange jet engine is likely to generate in light of uncertain oil and carbon prices in 2030 by applying Robust Design Theory to different combinations of the aforementioned technologies. Unlike profit, which is calculated using the Surplus Value methodology, optimising Direct Operating Cost could result in a lower utilisation and flight speed in order to reduce fuel consumption without taking the effect on revenue into account ${ }^{10}$.
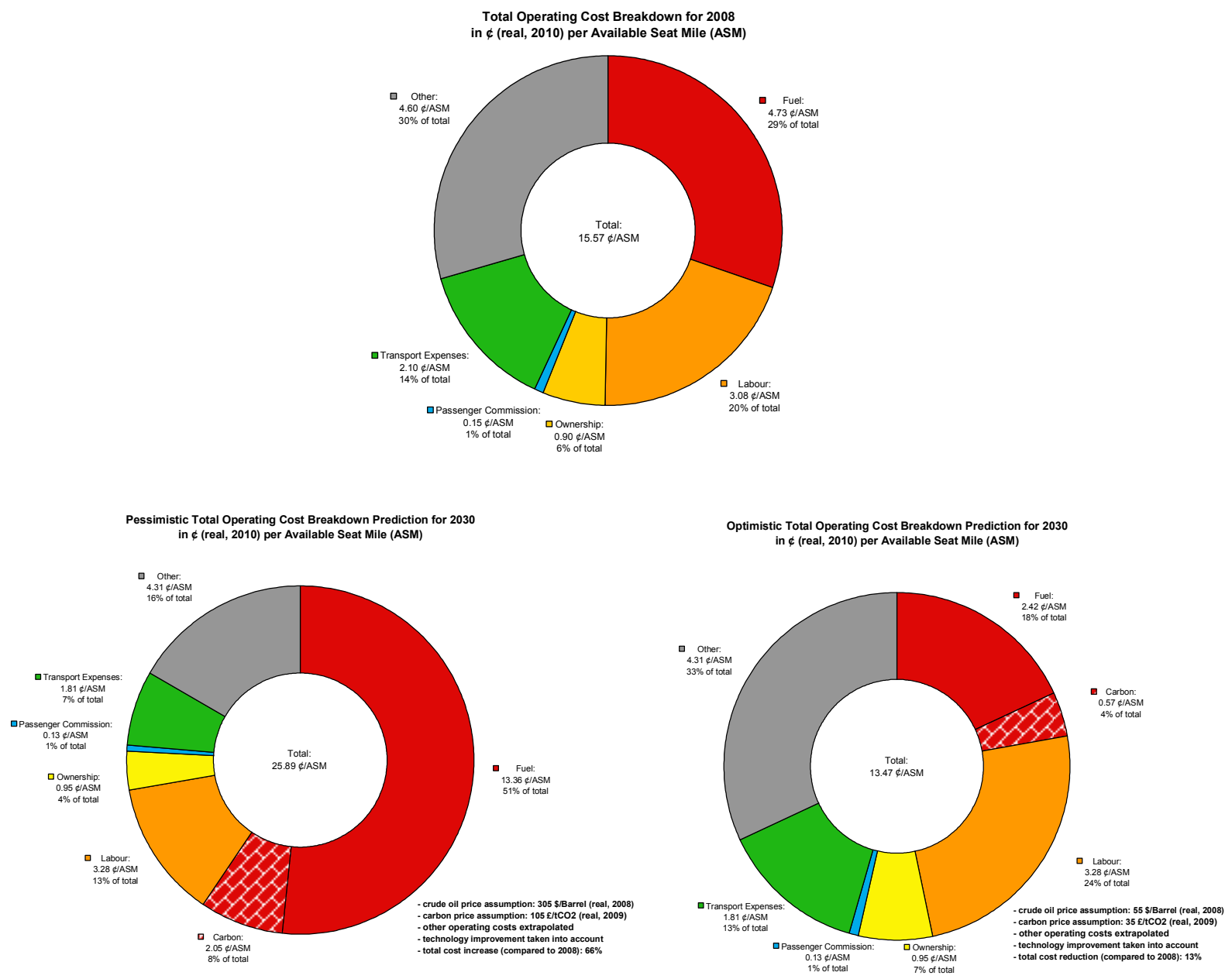

Figure 5. Total Operating Cost Pie Charts for 2008 and a Pessimistic \& Optimistic Prediction for 2030 (based on ATA* data for U.S. airlines and other sources ${ }^{4,5}$ )

\section{Modelling}

Although 2030 is less than two decades away, the author has chosen this timeframe because 2025 to 2030 is the likely service entry window for the next generation of short-range aircraft ${ }^{5}$. In the 2020s, all the technologies mentioned will also be mature enough to potentially be included in such an airframe. The author does not intend to make any prognoses beyond 2030 because of the unpredictability of many factors thereafter, not just oil and carbon prices but also technological capabilities and aircraft rollout dates ${ }^{5}$.

In order to find a strategic engine design that is robust with regard to fuel and carbon price uncertainty in 2030, a hierarchical Surplus Value model will be created that models the economics of the aircraft, its propulsion system and the advanced technologies within the engines. This will form the basis of the optimisation loop depicted in Fig. 6 on the next page to find the optimum technology combination for three different robustness metrics ${ }^{18}$ in which the trade-off between performance maximisation and performance variability is weighted differently.

Although the reader might expect the largest bypass ratio to produce the most robust design, the optimum solution is not straightforward because many design trade-offs are involved: as the flight speed affects the number of flights per day and hence the revenue, the optimisation loop will have to trade flight speed against fuel and $\mathrm{CO}_{2}$ costs as well as noise charges at airports ${ }^{19}$. 


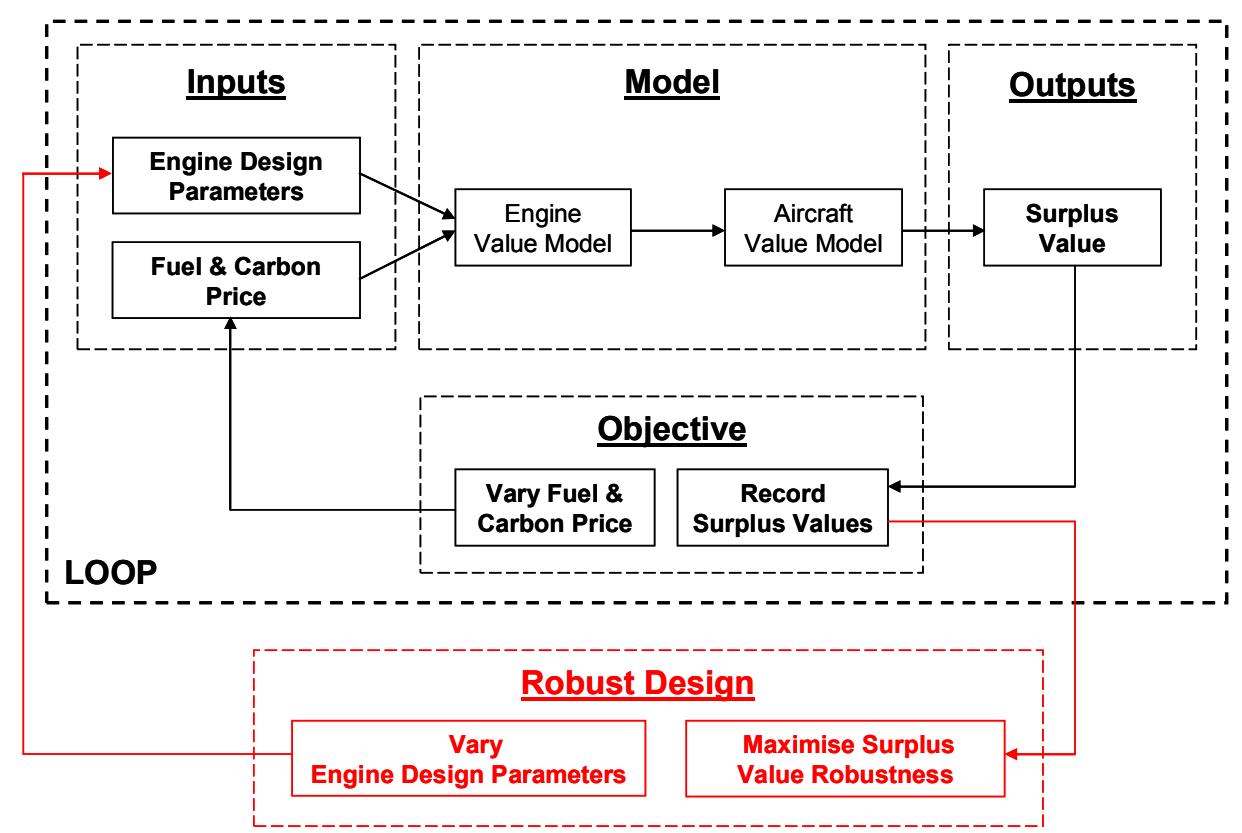

Figure 6. Robust Design Optimisation Loop

\section{Acknowledgments}

The author would like to thank his co-authors for their intellectual contribution to this project. This project is funded by the British Engineering and Physical Sciences Research Council (EPSRC) and Rolls-Royce plc.

\section{References}

${ }^{1}$ Advisory Council for Aeronautics Research in Europe (ACARE), "Aeronautics and Air Transport: Beyond Vision 2020 (Towards 2050)," ACARE, 2010.

${ }^{2}$ Sorrell, S., Speirs, J., Bentley, R., Brandt, A., Miller, R., "Global Oil Depletion," United Kingdom Energy Research Centre (UKERC), 2009.

${ }^{3}$ Airbus, "Global Market Forecast 2009-2028," Airbus S.A.S., 2009.

${ }^{4}$ Donovan, S., Petrenas, B., Leyland, G., Caldwell, S., Barker, A., Chan, A., Dempsey, L., "Price Forecasts for Transport Fuels and other Delivered Energy Forms," Auckland Regional Council, 2009.

${ }^{5}$ Committee on Climate Change (CCC), "Meeting the UK Aviation Target - Options for Reducing Emissions to 2050," CCC, 2009.

${ }^{6}$ Rehrl, T., Friedrich, R., "Modelling Long-Term Oil Price and Extraction with a Hubbert Approach: The LOPEX Model," Energy Policy, Vol. 34, No. 15, 2006, pp. 2413-2428.

7United States Energy Information Administration (EIA), "Annual Energy Outlook 2010," EIA, 2010.

${ }^{8}$ House of Commons Transport Committee, "The Future of Aviation," House of Commons Transport Committee, 2009.

${ }^{9}$ Anastasi, L., Dickinson, H., Kass, G., Smith, K., Stein, C., "Aviation and the Environment," Parliamentary Office of Science and Technology (POST), 2003.

${ }^{10}$ Bower, C. G., Kroo, I. M., "Multi-Objective Aircraft Optimization for Minimum Cost and Emissions over Specific Route Networks," International Congress of the Aeronautical Sciences (ICAS), AIAA, Reston, USA, 2008.

${ }^{11}$ Scheelhaase, J. D., Grimme, W. G., "Emissions Trading for International Aviation - An Estimation of the Economic Impact on Selected European Airlines," Journal of Air Transport Management, Vol. 13, No. 5, 2007, pp. 253-263.

${ }^{12}$ Department for Transport (DfT), "The Future of Air Transport," DfT, 2003.

${ }^{13}$ Van Hasselt, M., Van der Zwan, F., Ghijs, S., Santema, S., "Developing a Strategic Framework for an Airline Dealing with the EU Emission Trading Scheme," AIAA Aviation Technology, Integration and Operations Conference (ATIO), AIAA, Reston, USA, 2009.

${ }^{14}$ Rolls-Royce, The Jet Engine, $6^{\text {th }}$ ed., Rolls-Royce plc, London, 2005, pp. 266, 268, 275, 277.

${ }^{15}$ Schimming, P., "Counter Rotating Fans - An Aircraft Propulsion for the Future," Journal of Thermal Science, Vol. 12, No. 2, 2003, pp. 97-103.

${ }^{16}$ Steffens, K., "Advanced Compressor Technology - Key Success Factor for Competitiveness in Modern Aero Engines," International Symposium on Air Breathing Engines (ISABE), AIAA, Reston, USA, 2001. 
${ }^{17}$ Faleiro, L., "Beyond the More Electric Aircraft," Aerospace America, Vol. 5, No. 9, 2005, pp. 35-40.

${ }^{18}$ Keane, A. J., Nair, P. B., Computational Approaches for Aerospace Design, $1^{\text {st }}$ ed., John Wiley \& Sons, Chichester, UK, 2005, Chaps. 1, 8.

${ }^{19}$ Collopy, P. D., "Surplus Value in Propulsion System Design Optimization," AIAA Paper, 97-3159, 1997. 